\title{
Clinical Recovery and Sleep Architecture Degradation
}

\author{
Vladimir C. Hachinski, Mortimer Mamelak and John W. Norris
}

\begin{abstract}
We achieved a unique and timely recording of cerebral activity in a 70 year old woman immediately pre- and post-stroke, while studying the effect of acute cerebral infarction on sleep-electroencephalogram (EEG) patterns. Normal patterns, except for increased wakefulness, were recorded during two pre-infarct polysomnograms. Immediately following cerebral infarction increased delta activity was recorded from the infarcted hemisphere only. Initially, REM sleep could not be recorded from either side; however, on the third post infarct day REM sleep returned. Background EEG levels from both hemispheres became progressively slower, flatter and simpler. In addition, sleep spindles and the distinctive saw-tooth wave forms of sleep almost disappeared. At one year post-stroke sleep-EEG rhythm recordings from both hemispheres became more similar except for persisting delta activity from the left hemisphere. Unexpected deterioration of sleep-EEG pattern recordings from the undamaged hemisphere taken during the patient's clinical recovery remains unexplained. Serial sleep recording may facilitate the study of brain recovery, activity and reorganization following stroke.
\end{abstract}

RÉSUMÉ: Récupération clinique et dégradation de l'architecture du sommeil Nous avons réussi un enregistrement unique et opportun de l'activité cérébrale chez une femme âgée de 70 ans immédiatement pré- et post-accident cérébrovasculaire, pendant l'étude des effets de l'infarctus cérébral aigu sur le tracé électro-encéphalographique (EEG) enregistré pendant le sommeil. Un tracé normal, sauf pour une augmentation de l'état de veille, a été enregistré pendant deux polysomnogrammes pré-infarctus. Immédiatement après l'infarctus cérébral, une augmentation de l'activité delta a été enregistrée provenant de l'hémisphère infarcisé seulement. Initialement, le sommeil REM n'a pu être enregistré d'un côté comme de l'autre; cependant, le troisième jour post-infarctus, le sommeil REM est revenu. Le rythme de fond de l'EEG des deux hémisphères a ralenti progressivement, s'est aplati et simplifié. De plus, le fuseaux et les ondes en dents de scie caractéristiques du sommeil ont presque disparu. Un an après l'accident cérébrovasculaire, l'enregistrement du rythme électro-encéphalographique des deux hémisphères est devenu plus semblable, sauf pour la persistance d'activité delta à l'hémisphère gauche. Une détérioration imprévue du rythme EEG du sommeil à l'hémisphère non endommagé enregistré pendant la récupération clinique de la patiente demeure inexpliquée. Des enregistrements sériés pendant le sommeil pourraient faciliter l'étude de la récuperation, le l'activité et de la réorganisation cérébrales à la suite d'un accident cérébrovasculaire.

Can. J. Neurol. Sci. 1990; 17: 332-335

Serial all-night sleep-EEG patterns of post-acute cerebrovascular lesion patients were recorded ${ }^{1-3}$ to determine if clinical outcome in stroke could be predicted from initial sleep-EEG changes, as is possible in post-traumatic coma. ${ }^{5-7}$ We report one year of polysomnographic data on a patient following massive left sided cerebral infarction. These data are unique because sleep recordings were obtained the week before, and after cerebral infarction, and because of the length of the study.

\section{Methods}

Polysomnographic recordings were obtained throughout the second and third nights following admission and again on the 2nd to 4th, 9th, 10th, 30th, 31 st, 52nd and 53rd nights following stroke. At one year three additional consecutive all-night recordings were obtained. The electrode montage recommended by Rechtschaffen and Kales ${ }^{4}$ for EEG recordings during sleep were modified to a bilateral parasaggital array, referring right and left frontal, central, and occipital leads to the ipsilateral ear. This method was chosen to minimize the contamination of the electrical activity recorded from one hemisphere by that of the other. The electro-oculograph and the submental electromyograph (EMG) were recorded by the usual techniques. ${ }^{4}$ Sleep records were scored independently by two experienced technicians according to international criteria ${ }^{4}$ using 20 second epochs. Our single modification was to score stage 2 sleep using sleep spindles as our criterion disregarding $\mathrm{K}$ complexes, since in previous stroke records these complexes were often difficult to distinguish from delta waves. Each night's record was scored using EEG data from the right central lead (undamaged hemisphere) and from the left central lead (damaged hemisphere). The number of spindles of one-half second or more in duration was counted separately on both sides of the brain and their density,

From the MacLachlan Stroke Unit (V.C.H., J.W.N.); Sleep Laboratory (M.M.), Sunnybrook Medical Centre, The University of Toronto, Toronto Received September 15, 1989. Accepted in final form February 20, 1990

Reprint requests to: Dr. V. C. Hachinski, University Hospital, P.O. Box 5339, London, Ontario, Canada N6A 5A5 
i.e., their number per minute of NREM sleep, was then calculated. The REM density was determined by measuring the percentage of two second REM mini-epochs having one or more rapid eye movement(s). The total sleep time refers to the sum of stages 1 to 4, REM, and movement time.

\section{Case History}

A.W., a 70 year old right-handed female, was admitted to the stroke intensive care unit following a 10 minute episode of aphasia. Six years earlier, she had undergone an aorto-femoral bypass, and during the two years prior to admission she was known to be hypertensive. Her medical history was otherwise unremarkable. On physical examination at admission, she was fully conscious, the blood pressure was $200 / 90 \mathrm{~mm}$ $\mathrm{Hg}$, and there were clinical and radiological signs of left ventricular hypertrophy. The awake EEG was normal.

Transient aphasia recurred three hours after admission. Further aphasic episodes recurred on the 6th and 7th days post admission, while hypertension remained despite medication. Four hours after her last aphasic episode she was drowsy with a dense right hemiplegia, hemianesthesia, homonymous hemianopia and global aphasia. A computerized tomogram of the brain showed complete infarction in the left middle cerebral artery territory. The thalamus was not involved. Ten hours later her lumbar cerebrospinal fluid pressure measured $190 \mathrm{~mm}$ of water; protein $51 \mathrm{mg} \%$ and there were no cells. Alertness was regained on day 3, while daytime EEG showed continuous theta and delta activity over the left fronto-temporal region and the photic driving response over the left hemisphere was impaired.

Expressive aphasia, right hemiparesis, homonymous hemianopia and hemianesthesia remained one year following stroke. The patient was, however, alert and able to communicate her needs.

\section{RESULTS}

The most dramatic immediate result from the stroke was the dissolution of the sleep architecture seen in recordings from both sides of the brain, particularly from the damaged side. On the second post-stroke night, REM sleep could not be scored from either hemisphere (Figure 1). Flattening of the EMG indicated recurrent periods of atonia, although both rapid eyc movements and saw-tooth waves were absent. The EEG indicated only theta and delta activity on the side of the lesion with delta activity accounting for about $75 \%$ of the recording time. Sleep spindles were virtually absent (Table 1). By contrast, on the undamaged hemisphere the duration of delta activity was unchanged, and the sleep spindles, although less plentiful, briefer and not as well formed, were still present in good number.

There was some return of the sleep patterns towards normal during the following nights. REM sleep was recorded again on the third night from both hemispheres and by the 9 th night, its duration had returned to the pre-stroke level. Similarly, by the 9 th night, duration of the delta activity recorded from the infarcted hemisphere had decreased to about its pre-stroke level. Nevertheless, the sleep morphology continued to appear abnormal. A progressive deterioration set in, evident in the simplification, slowing and flattening of the background electroencephalographic rhythms as well as in the gradual disappearance of the distinctive wave forms of sleep - the saw-tooth wave spindles

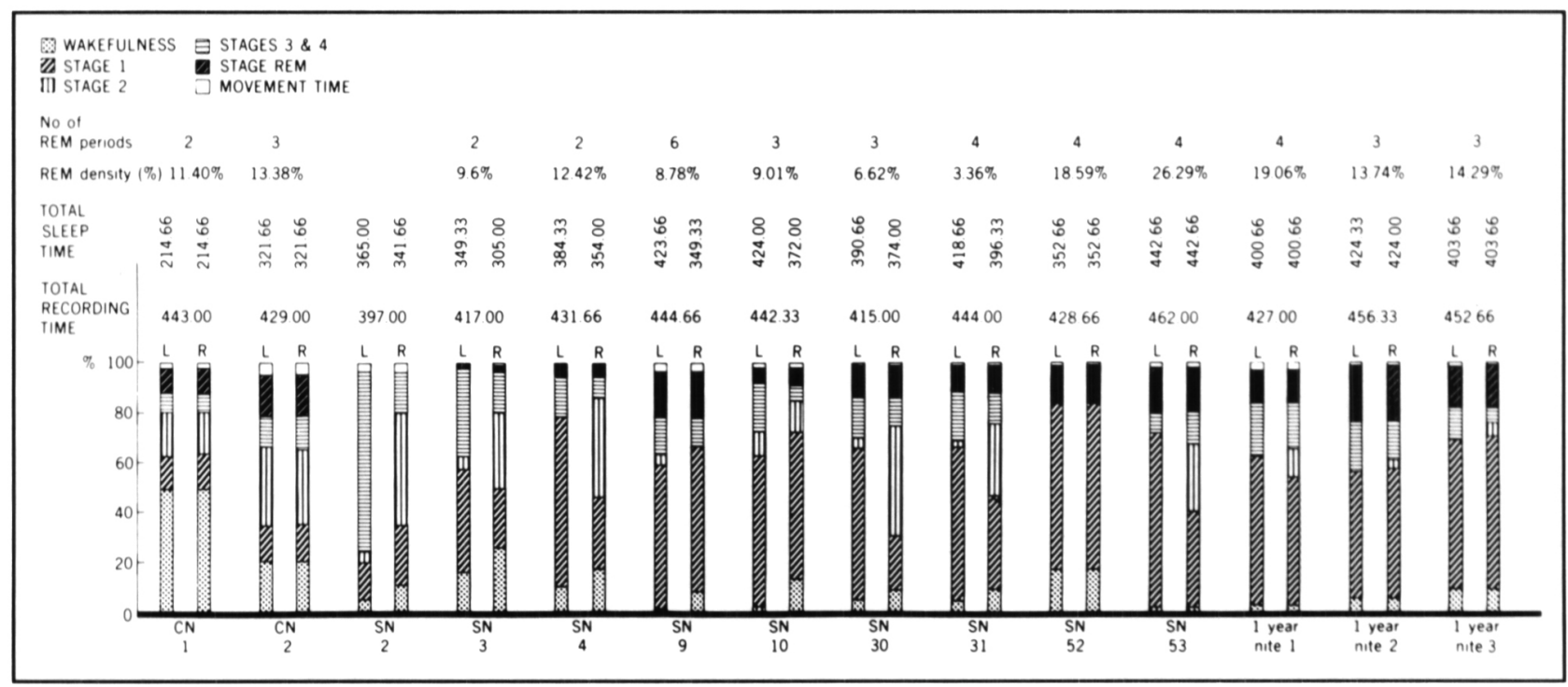

Figure I-Quantification of polysomnography before and after stroke

The increased proportion of stage 3 and 4 sleep from the left hemisphere is probably due to the admixure of continuing parhological slow' wave activity.

CN indicates control night. SN indicates stroke night.

Table 1: Number of Spindles

\begin{tabular}{|c|c|c|c|c|c|c|c|c|c|c|c|c|c|c|}
\hline & $\mathrm{CN}$ & $\mathrm{CN}$ & SN & SN & SN & $\mathbf{S N}$ & SN & SN & SN & SN & SN & $\mathrm{SN}+1$ & $\mathrm{SN}+1$ & $S N+1$ \\
\hline $\begin{array}{l}\text { RH } \\
\text { LH }\end{array}$ & $\begin{array}{l}177 \\
211\end{array}$ & $\begin{array}{l}321 \\
380\end{array}$ & $\begin{array}{c}230 \\
13\end{array}$ & $\begin{array}{c}166 \\
13\end{array}$ & $\begin{array}{c}195 \\
9\end{array}$ & $\begin{array}{c}152 \\
13\end{array}$ & $\begin{array}{l}62 \\
28\end{array}$ & $\begin{array}{c}291 \\
15\end{array}$ & $\begin{array}{c}161 \\
8\end{array}$ & $\begin{array}{l}0 \\
0\end{array}$ & $\begin{array}{c}109 \\
0\end{array}$ & $\begin{array}{c}30 \\
0\end{array}$ & $\begin{array}{c}23 \\
0\end{array}$ & $\begin{array}{c}11 \\
0\end{array}$ \\
\hline
\end{tabular}

$\mathrm{CN}=$ Control Night $\quad \mathrm{SN}=$ Stroke Night $\quad \mathrm{SN}+1=$ Stroke Night One Year Later $\quad \mathrm{RH}=$ Right Hemisphere $\quad$ LH $=$ Left Hemisphere 
(Figures 2-4). The sleep spindles on the infarcted side of the brain disappeared almost completely immediately after the stroke. With the decline in duration of delta activity, the electrical patterns displayed during sleep by this hemisphere progressed towards a pattern consisting largely of theta activity with intermittent periods of delta. Initially, there was some spindle activity on the uninfarcted side, although it also was reduced. Spindling gradually ceased in this hemisphere as well, and by night 53 virtually no spindles could be counted (Table 1). Spindle counts from the uninfarcted hemisphere varied greatly from night to night during the first few post-stroke weeks but at one year they were consistently very low.

Saw-tooth waves followed a similar course. On the third poststroke night they could still be readily distinguished in recordings from both hemispheres, gradually fading and disappearing into the background rhythms (Figures $2-4$ ). These rhythms also became progressively less complex and narrower in their range of frequencies and amplitudes. One year following stroke, the sleep-EEG patterns recorded from the two hemispheres became more similar, except that there remained more delta activity on the left (Figure 4).

\section{Discussion}

It has been reported ${ }^{5-7}$ that the post-traumatic coma patients who tended to deteriorate clinically were those whose all-night sleep-EEG pattern recordings showed continuous slow wave activity or alternating periods of slow and fast wave activity. Recovery tended to occur in patients showing well-differentiated patterns of normal sleep or those in whom these patterns gradu-

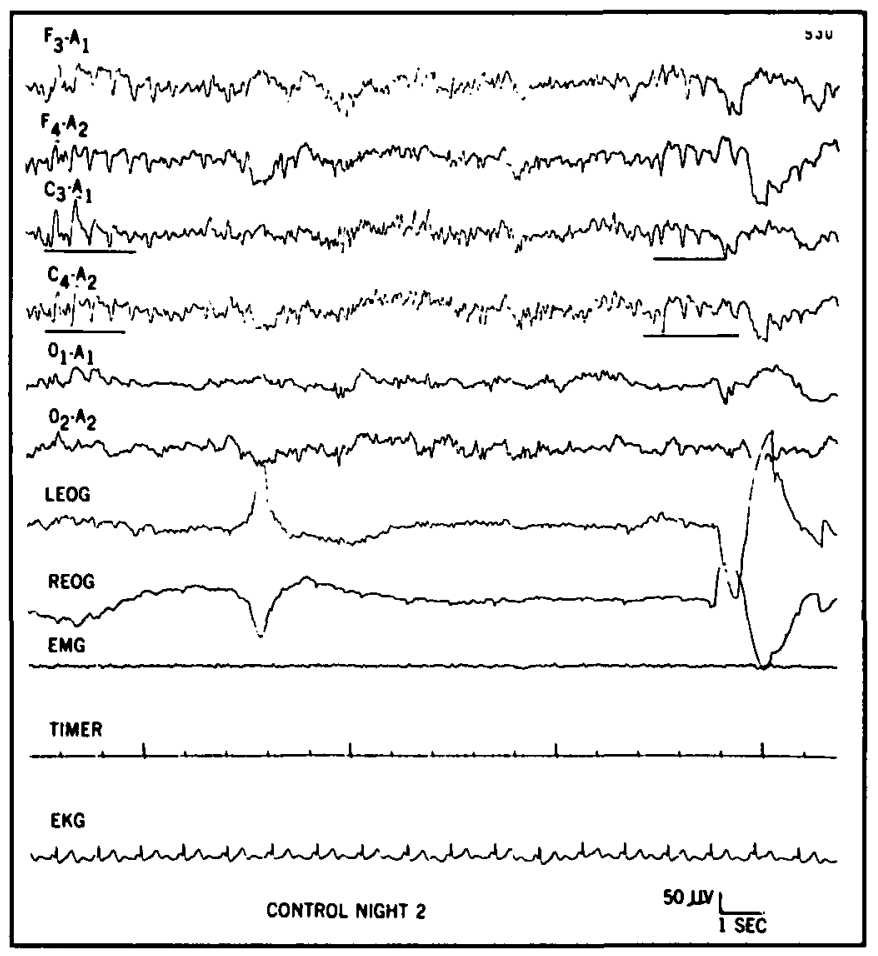

Figure 2-Pre-stroke pattern

Polysomnographic recording on control night 2. Saw-tooth waves are underlined.

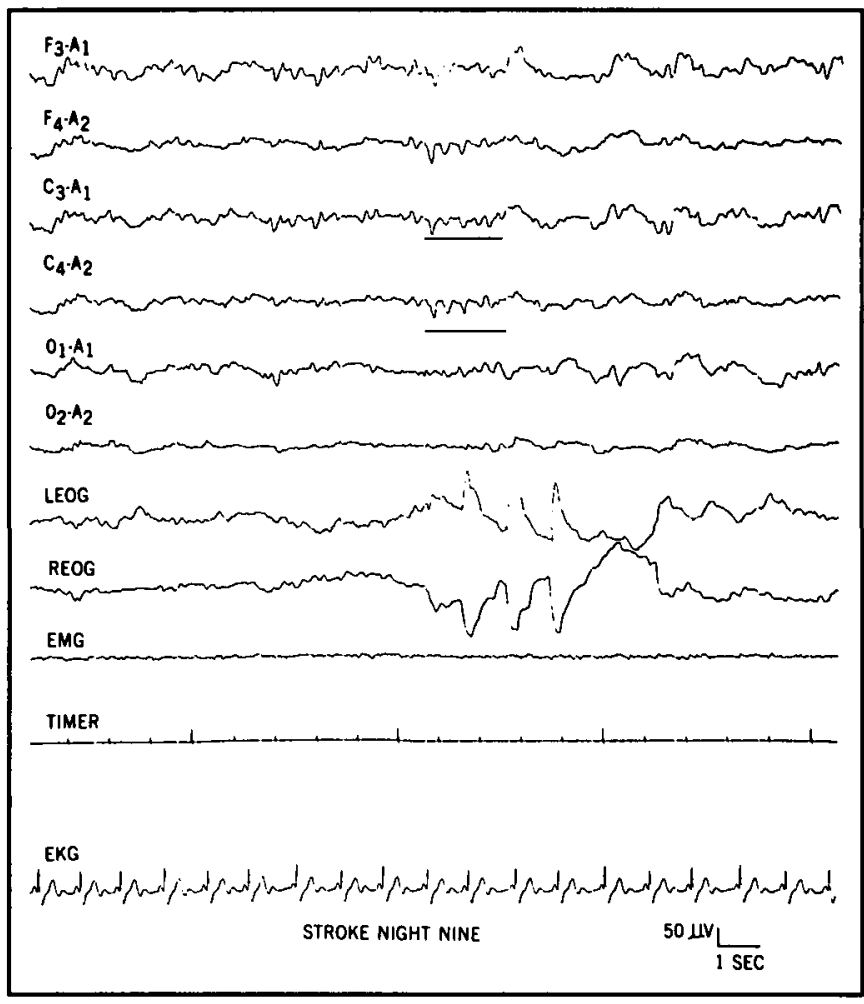

Figure 3-Post-stroke pattern

Polysomnographic recording on post-stroke night 9. Saw-tooth waves are underlined. Note the decrease in the amplitude and range of frequencies of the background rhythms and flattening of the sawtooth waves.

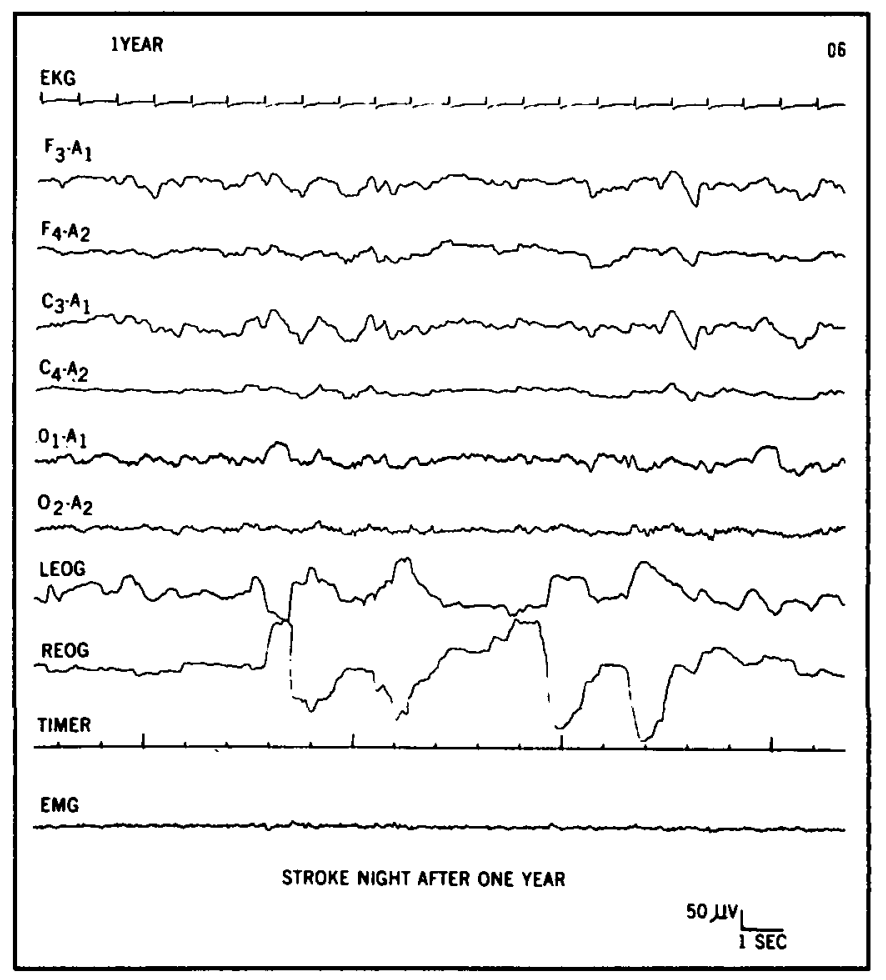

Figure 4-Post-stroke pattern

Polysomnographic recording I year after the stroke. Saw-tooth waves have disappeared. The activity from both hemispheres has become virtually indistinguishable except for the continuing slow wave activity from the lefi hemisphere. 
ally appeared. Our study aimed to determine if similar changes could be observed in stroke. Our preliminary studies have partially confirmed ${ }^{\mathrm{l}-3}$ that these recordings can prove useful in predicting clinical outcome in patients with impairment of consciousness following stroke.

Marked increase in delta activity recorded from only the infarcted hemisphere, and the resolve-speed of this activity, are observations which have already been made by others in serial studies of the daytime EEG after stroke. 8 Since increased delta activity in both night and day recordings stems from the same pathological process, it is not surprising that the evolution in the two types of recordings should follow a similar course. The pathological delta activity recorded after stroke in our patient was difficult to distinguish from the normal delta activity of sleep.

During the first two weeks following stroke, very rapid changes were also present in REM sleep patterns. On the second post stroke night, REM sleep could not be scored in recordings from either hemisphere; however, by the 9 th night its duration had returned to the pre-infarction level (Figure 1). The disappearance of REM sleep was likely due to the specific absence of both rapid eye movements and saw-tooth waves from the recordings, rather than due to any failure of the pontine REM sleep generator, since the persisting periods of motor atonia indicated by the flattening of the EMG suggested that the generator was still partially active. On the third post stroke night, REM sleep was again readily scored; both rapid eye movements and saw-tooth waves were visible. Nevertheless, although REM sleep duration rapidly returned to its baseline level and thereafter remained very constant, saw-tooth activity gradually faded in keeping with the progressive simplification and flattening of the EEG rhythms which commenced after stroke. The transient disappearance of the rapid eye movements after stroke cannot be explained. In cats ${ }^{9}$ and man, ${ }^{10}$ there is evidence that the visual cortex and visual association areas are necessary for elaboration of these movements. Perhaps in our patient, a transient functional depression of these areas occurring after stroke accounts for their disappearance.

Most surprising was the rapid deterioration of the EEG rhythms on the uninfarcted, supposedly undamaged, side of the brain. Progressive decay in spindle activity on this side of the brain following stroke (Table 1), attenuation and eventual disappearance of the saw-tooth waves, and the slowing, flattening, and simplification of the electroencephalographic rhythms, best illustrate that unexpected finding. These changes also occurred on the infarcted side of the brain, but can be attributed to tissue damage following the vascular occlusion; one would not expect them in recordings from the undamaged hemisphere as well.

We propose that diaschisis accounts for the rapid deterioration of electrical activity recorded from the undamaged side of the brain. As originally defined by von Monakow, 11 diaschisis refers to the transient depression of function which takes place in remote areas of the brain, including the opposite hemisphere, following a focal injury. In practice, diaschisis has been mea- sured by the fall in metabolism and blood flow to these regions. ${ }^{12,13}$ Although there is little doubt that diaschisis occurs after cerebral infarction, whether or not it is a transient phenomenon remains to be determined. The answer may depend upon the size and nature of the lesion and upon factors presently unknown. Serial sleep-EEG rhythm recordings may offer a simple method for studying brain activity, recovery and reorganization after stroke.

\section{ACKNOWLEDGEMENT}

Dr. Hachinski is a Career Investigator of the Heart and Stroke Foundation of Ontario. This work was supported by Grant \#PR611 Ontario Ministry of Health.

We thank Dr. Roger Broughton for his advice, Mr. Richard Kwan and Mrs. Victoria Caruso Price for their technical help, and Mrs. Mary Ann Kucherawy for much appreciated editorial work.

\section{REFERENCES}

1. Hachinski VC, Mamelak M, Norris JW. Sleep morphology and prognosis in acute cerebrovascular lesions. In: Meyer J, Lechner H, Reivich M, eds. Cerebral vascular disease. AmsterdamOxford: Excerpta Medica, Elsevier, 1977; 69-71.

2. Hachinski VC, Mamelak M, Norris JW. Prognostic value of sleep morphology in cerebral infarction. I $n$ : Meyer J, Lechner $\mathrm{H}$, Reivich $M$, eds. Cerebral vascular disease. Proceedings of the 9th international Salzburg conference on cerebral vascular disease. North Holland: Excerpta Medica, Elsevier, 1979; 287-291.

3. Hachinski VC, Mamelak M, Norris JW. Sleep architecture and recovery from stroke. In: Masland RL, Portera-Sanchez A, Toffano G, eds. Neuroplasticity: a new therapeutic tool in the CNS pathology. Fidia Research Series, Vol. 12. Padova: Liviana Press 1987; 179-184.

4. Rechtschaffen A, Kales A. A manual for standardized terminology, techniques and scoring system for sleep stages of human subjects. U.S. Department of Health, Education and Welfare Publication No. 204, U.S. Government Printing Office, Washington, D.C., 1968.

5. Bergamasco B, Bergamini L, Doriguzzi T, et al. EEG-sleep patterns as a prognostic criterion in post-traumatic coma. Electroencephalo Clin Neurophysiol 1968: 24: 374-377.

6. Bricolo A, Gentilomo A, Rosadini G, et al. Long-lasting posttraumatic unconsciousness. A study based on nocturnal EEG and polygraphic recording. Acta Neurol Scand 1968; 44: 513-532.

7. Lessard CS, Sances A Jr, Larsen SJ. Period analysis of EEG signals during sleep and post-traumatic coma. Aerospace Med 1974; 45: 664-668.

8. Kiloh L, McComas A, Osselton J. Clinical Electroencephalography, 3rd Edition. London: Butterworths, 1972; 125-138.

9. Jouvet M. Neurophysiology of the states of sleep. Physiol Rev 1967; 47: 117-177.

10. Greenberg R. Cerebral cortex lesions: The dream process and sleep spindles. Cortex 1966; 2: 357-366.

11. Reivich $\mathrm{M}$, Jones $\mathrm{S}$, Castano $\mathrm{T}$, et al. A model of diaschisis in the cat using middle cerebral artery occlusion. In: Ingvar $\mathrm{H}$, Lassen V, eds. Cerebral function, metabolism and circulation. Copenhagen: Munhsgaard, 1977; 242-243.

12. Slater R, Reivich $M$, Goldberg $H$, et al. Diaschisis with cerebral infarction. Stroke 1977; 8: 684-690.

13. Heiss DW, Zeiler $K$, Havelec $L$, et al. Long term prognosis in stroke related to cerebral blood flow. Arch Gen Neurol 1977; 34: $671-676$. 